\title{
Proceeding
}

7th INSHS International Christmas Sport Scientific Conference, 9-12 December 2012. International Network of Sport and Health

Science. Szombathely, Hungary

\section{High diving: evaluation of water impact and considerations on training methods}

\author{
SALVATORE NAPOLITANO , PIO ALFREDO DI TORE, GAETANO RAIOLA \\ Department of Human, Philosophical and Education Sciences (DISUFF) University of Salerno, Italy
}

\begin{abstract}
Napolitano S, Di Tore PA, Raiola G. High diving: evaluation of water impact and considerations on training methods. J. Hum. Sport Exerc. Vol.8, No. Proc2, pp. S283-S289, 2013. High diving is a sport that became popular in recent years. Since 2013, FINA has added it to the official list of swimming disciplines. This pilot work focuses on two specific aspects of the High diving: 1. The impact with water: in high diving competitions the platforms are located at a height between 25 and 28 meters. The impact with the water exposes muscles, articulations and the whole athlete body to abnormal solicitations (Snyder \& Snow, 1967). 2. The lack of opportunities for athletes to train in an environment similar to that in which the performance occurs: divers can practice only on the day before the competition; they can't practice on a daily basis (Paulev \& Zubieta-Calleja, 2007). The aim of this study is to develop a training methodology that takes into account these two peculiar difficulties and, on a scientific basis, looks for methodological and technological supports. The approach of research is integrated and composed by two distinct methods: With regard to the influence of impact with the water, the coefficient of impact was calculated using preexisting data in scientific literature, by reference to studies, conducted in the aeronautical field, concerning the impact of the water on the objects. With regard to the technical side, three international competitions have been studied using video analysis methodology: 2 events related to Red Bull Cliff Diving World Series, and an event relative to Maremeeting Campionato Mondiale di Cliff Diving di Furore (SA). Aim of video analysis was to analyze the various segments of technical execution of each single dive executed by the athlete during the competition in order to better prepare and individualize the strengths and weaknesses of the athlete in each single execution. The athlete's body takes the maximum charge when it is partially submerged. This is verified with the following numbers: 12994,525 [N] in a "dt" of 0,001s (at 9,14 $\mathrm{m} / \mathrm{s}, 4,25 \mathrm{~m}$ in height, maximum force 3661,86 [N]). In other words, a diver of $80 \mathrm{~kg}$ with a surface impact equal to $0,000508 \mathrm{~m}^{2}$ (foot in hyperextension) jumping from a height of $28 \mathrm{~m}$ finds its highest stimuli at $12994,525 \mathrm{~N}$ at $1.64 \mathrm{mt}$ of water penetration. The duration of the maximum stimuli is equal to 0.001 seconds. As is easily understood, the diver's body, even for a short time, is subject to a notable stimuli. Based on the results, it is possible to develop a model that, given height, weight and anthropometric values: 1.Calculate the body segment that will suffer the most stress on impact. 2 . Calculate the changes in the coefficient of impact based on the exposed surface. Also constructed model may help athletes to develop a type of training that protects privileged way in the body segments most vulnerable to and including and prevent the consequences of any errors. Key words: HIGH DIVING, WATER IMPACT, TRAINING METODOLOGY, VIDEOANALYSIS.
\end{abstract}

Corresponding author. Gaetano Raiola, Via Berenice 11, Napoli, Italy.

Email: raiolagaetano@libero.it

7th INSHS International Christmas Sport Scientific Conference, 9-12 December 2012. International Network of Sport and Health Science. Szombathely, Hungary.

JOURNAL OF HUMAN SPORT \& EXERCISE ISSN 1988-5202

(c) Faculty of Education. University of Alicante

doi:10.4100/jhse.2012.8.Proc2.30

VOLUME 8 | Proc2 | 2013 | S283 


\section{INTRODUCTION}

In high diving competitions the platforms are placed at a height that measures from 28 meters: it can imagine the impact with the water at such velocity $(24 \mathrm{~m} / \mathrm{s})$ that exposes the muscles and the articulations and all the soft parts of the whole organism to abnormal solicitations that must be absorbed in tenths of a second.

This pilot work has calculated the influence of the impact with water in high divers and the eventual consequences.

High diving, or cliff diving, is a sport that has become very popular in the last fifteen years, and beginning in 2013, in light of the World Swimming Championships, FINA has added it to the official list of swimming disciplines.

This highly spectacular discipline complies a series of motor and psychological abilities which imply constant and meticulous preparation on the athlete's part.

According to technical trainers and athletes, a growing need to analyze athletic preparation has occurred. If it considers that divers can practice only the day before the competition and not have the possibility to practice on a daily basis, as in other sports.

Due to this, we've come to need as many elements as possible to support their performance. The aim of the study is to analyze the various segments of technical execution of each single dive executed by the athlete during the competition in order to better prepare and individualize the strengths and weaknesses of the athlete in each single execution.

In modern sports the trainer's need to have useful data to analyze the skills of their athletes is growing.

When considering high diving, it comes to miss the technical analysis of coded methodological performance for the individualization of errors, which is usually left to the discretion of the singular athletes.

The goal of this study is to create a methodological model that will fill, through video analysis, acquiring and elaborating a certain amount of data collected relative to each performance.

The impact coefficient was calculated using pre existing data found in literature and a series of parameters that we will see later on. Wanting to evaluate the weight that the diver's body takes on, we've also referred to studies in the aeronautical fields on water impact on objects.

Consider the diver as a cylinder, long and slim (1.71 $\mathrm{m}$ in height) and weighing $80 \mathrm{~kg}$ and a fall from a height of 28 meters.

In the "in air" phase, consider " $g$ " (gravitational acceleration) for which the impact velocity is given by $\mathrm{v} 0=\sqrt{ }\left(2^{*} \mathrm{~g}^{*} \mathrm{~h}\right) \mathrm{m} / \mathrm{s}$.

In the "water phase" consider the phenomenon of water being put into motion, ignoring any other phenomena that this actions might trigger (friction, etc.). The evaluation of charges is based on the momentum theorem. 
From the moment of impact short intervals of time are considered ( $\mathrm{dt}=0.001 \mathrm{~s}$ ), for each interval we've considered how far the object penetrated into the water and what water mass was being moved (in the interval "dt", impulse is equal to the quantity of motion) to then calculate force.

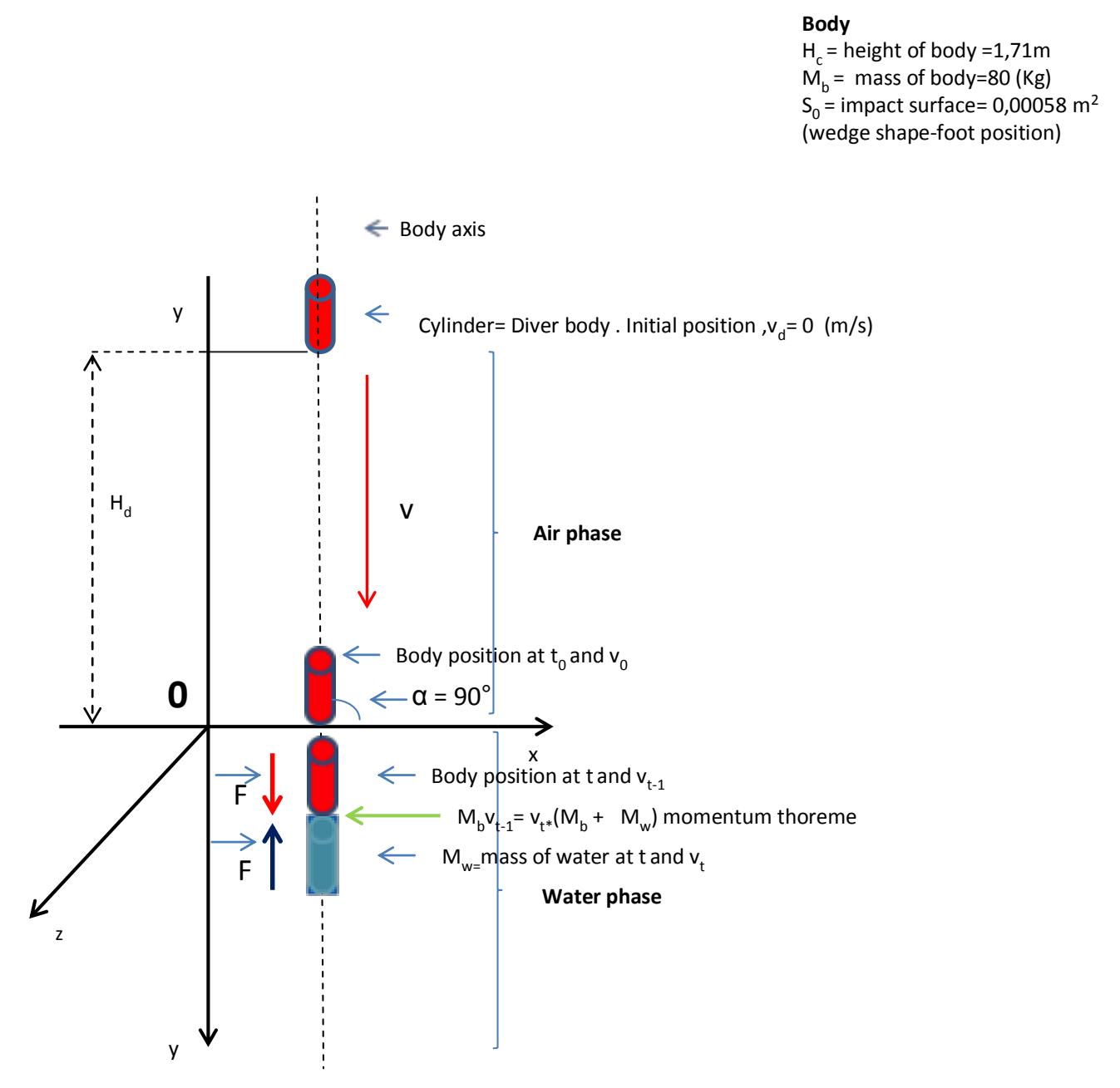

Figure 1. Diver body as a cylinder

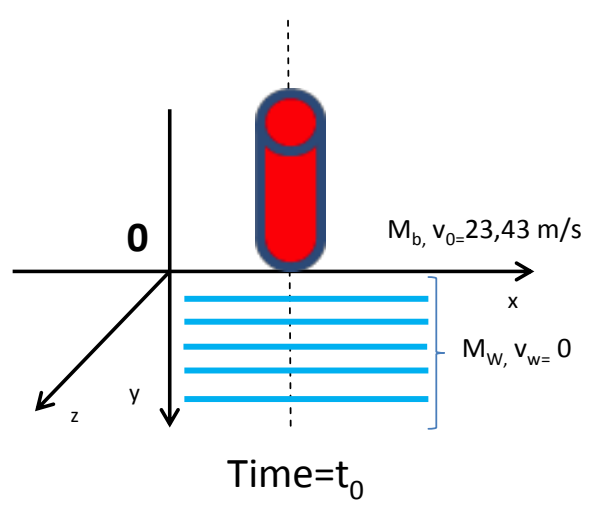

Figure 2. Water impact 


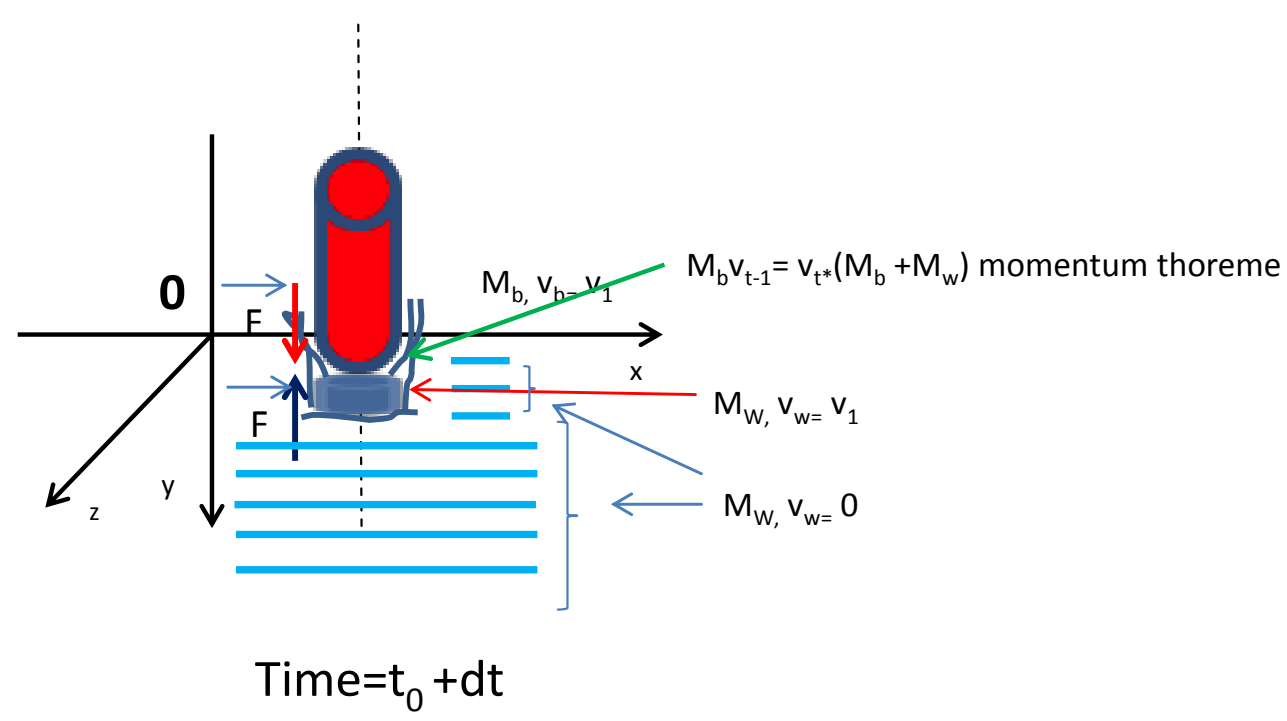

Figure 3. Post-impact.

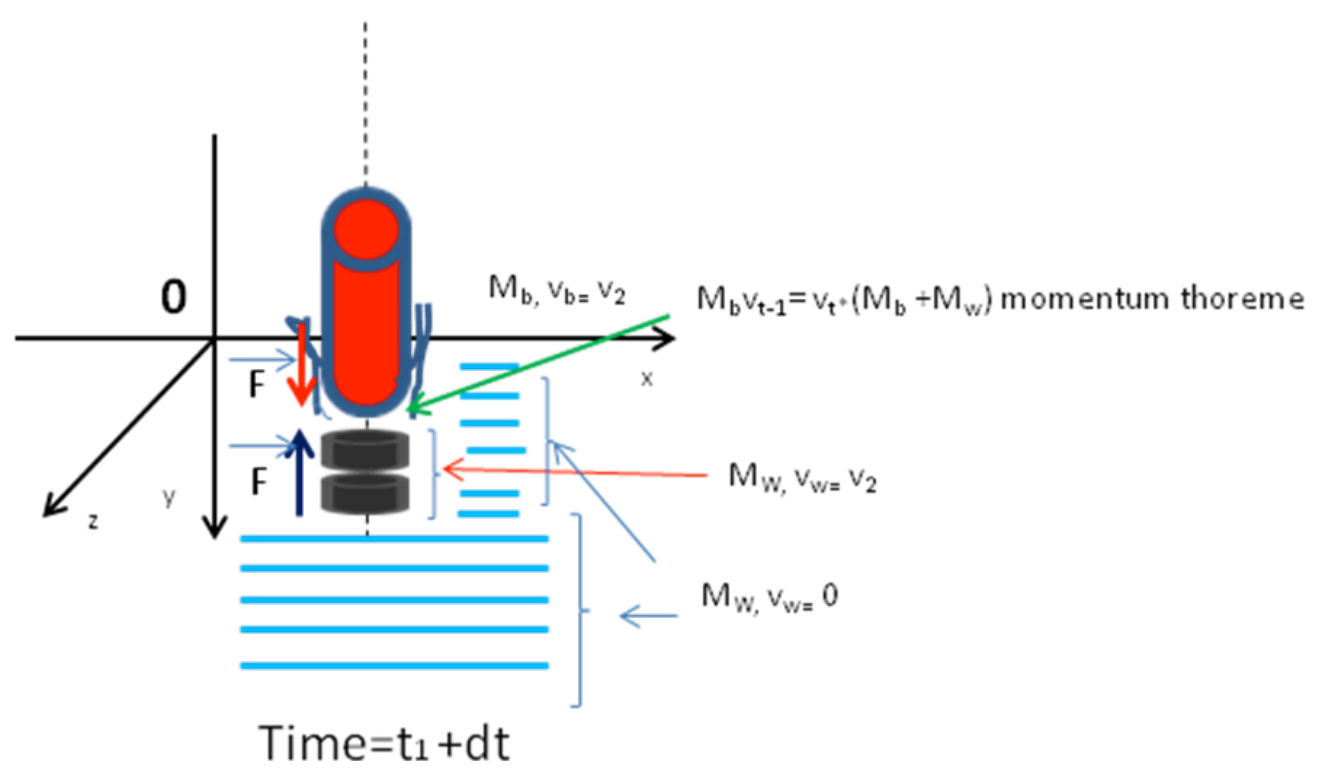

Figure 4. Momentum theorem

Another approximation considered was that the masses of water being put into motion in the following "dt" behaved in the same manner as masses moving at the same speed.

The results obtained were compared to those obtained using the formula from Von Karman for the calculation of the pressure of a "Flat Bottomed Float" and with experimental data taken for an impact at a speed of $9.14 \mathrm{~m} / \mathrm{s}$. 
The results obtained show that based on the surface impact; a body takes the maximum charge when it is partially submerged. This is verified with the following numbers: 12994,525 [N] in a "dt" of 0,001s (at 9,14 $\mathrm{m} / \mathrm{s}, 4,25 \mathrm{~m}$ in height, maximum force $3661,86[\mathrm{~N}])$.

Now we must evaluate $\mathrm{G}$ (vs. "dt") that the body takes on and its possible consequences.

Table 1. "Keyframes".

\begin{tabular}{|c|c|c|c|c|c|c|c|c|c|c|c|c|c|c|c|c|}
\hline & & & & & & & & Mbody & So & $\mathrm{Dt}$ & pi & gi & $\mathrm{roH} 2 \mathrm{O}$ & & & Press \\
\hline & & & & & & & & {$[\mathrm{kg}]$} & {$\left[\mathrm{m}^{2}\right]$} & {$[\mathrm{s}]$} & $\begin{array}{c}3,14159 \\
27\end{array}$ & {$\left[\mathrm{~m} / \mathrm{s}^{2}\right]$} & {$\left[\mathrm{kg} / \mathrm{m}^{3}\right]$} & & & {$\left[\mathrm{N} / \mathrm{m}^{2}\right]$} \\
\hline & & & & & & & & 80 & $\begin{array}{c}0,00050 \\
8\end{array}$ & 0,001 & & 9,80665 & 5998,21 & & & $\begin{array}{c}678381 \\
92\end{array}$ \\
\hline Vol_iniz & Ho & Vo & Eo & & & & & & & & & & & & & \\
\hline$\left[\mathrm{m}^{3}\right]$ & {$[\mathrm{m}]$} & {$[\mathrm{m} / \mathrm{s}]$} & {$[\mathrm{J}]$} & & & & & & & F_max & i_Fmax & $\underset{x}{X \_F m a}$ & & & & $\begin{array}{l}\text { Lav_Fm } \\
\quad \text { ax }\end{array}$ \\
\hline \multirow[t]{3}{*}{0,0} & 28 & 23,43 & 21966,9 & & & & & & & {$[\mathrm{~N}]$} & {$[-]$} & [m] & & & & {$\left[\mathrm{N}^{*} \mathrm{~m}\right]$} \\
\hline & & & & & & & & & & $\begin{array}{c}12994,5 \\
25\end{array}$ & 79 & 1,64 & & & & $\begin{array}{c}13298,3 \\
2\end{array}$ \\
\hline & $\begin{array}{l}\text { acc_Ine } \\
\mathrm{rz}\end{array}$ & $\underset{l}{\text { acc_gal }}$ & $\begin{array}{c}\text { acc_Co } \\
\text { rpo }\end{array}$ & o V_corp X_spost & $\begin{array}{l}\text { Vol } \\
\mathrm{H} 2 \mathrm{O}\end{array}$ & $\begin{array}{c}\text { Massa } \\
\mathrm{H} 2 \mathrm{O}\end{array}$ & $\begin{array}{c}\text { Quantit } \\
\text { à di } \\
\text { Moto }\end{array}$ & $\begin{array}{l}\text { Masse } \\
\text { in moto }\end{array}$ & V1 & F_1 & F_2 & $\begin{array}{c}\text { F_som } \\
\text { ma }\end{array}$ & Press & n_press & Lavoro & $\begin{array}{c}\text { Integral } \\
\text { e del } \\
\text { lavoro }\end{array}$ \\
\hline$\#$ & {$\left[\mathrm{~m} / \mathrm{s}^{2}\right]$} & {$\left[\mathrm{m} / \mathrm{s}^{2}\right]$} & {$\left[\mathrm{m} / \mathrm{s}^{2}\right]$} & {$[\mathrm{m} / \mathrm{s}] \quad[\mathrm{m}]$} & {$\left[\mathrm{m}^{3}\right]$} & {$[\mathrm{kg}]$} & {$\left[\mathrm{N}^{*} \mathrm{~s}\right]$} & {$[\mathrm{kg}]$} & {$[\mathrm{m} / \mathrm{s}]$} & {$[\mathrm{N}]$} & {$[N]$} & {$[\mathrm{N}]$} & {$\left[\mathrm{N} / \mathrm{m}^{2}\right]$} & {$[-]$} & {$\left[\mathrm{N}^{*} \mathrm{~m}\right]$} & {$\left[\mathrm{N}^{*} \mathrm{~m}\right]$} \\
\hline 1 & 9,80665 & 0,0000 & 9,8 & $23,4344 \begin{array}{c}0,02343 \\
4\end{array}$ & $\begin{array}{c}1,19 \mathrm{E}- \\
05\end{array}$ & 0,01188 & 1874,75 & 80,012 & 23,4309 & 278,439 & 278,439 & 556,9 & $\begin{array}{c}109621 \\
6\end{array}$ & 0,016 & 6,53 & 0,0 \\
\hline 25 & $\begin{array}{c}- \\
70,1462\end{array}$ & 0,0346 & $-70,2$ & $22,6468 \begin{array}{c}0,57985 \\
7\end{array}$ & $\begin{array}{c}0,00029 \\
5\end{array}$ & ${ }^{9} 0,29404$ & 1811,74 & 80,294 & 22,5638 & $\begin{array}{c}6634,67 \\
9\end{array}$ & $\begin{array}{c}6634,67 \\
9\end{array}$ & 13269,4 & $\begin{array}{c}261207 \\
82\end{array}$ & 0,385 & 150,25 & 1959,73 \\
\hline 50 & $\begin{array}{c}- \\
129,335\end{array}$ & 0,0681 & $-129,4$ & $20,0514 \begin{array}{c}1,11534 \\
1\end{array}$ & $\begin{array}{c}0,00056 \\
7\end{array}$ & 0,56558 & 1604,11 & 80,566 & 19,9106 & $\begin{array}{c}11261,0 \\
34\end{array}$ & $\begin{array}{c}11261,0 \\
34\end{array}$ & 22522,1 & $\begin{array}{c}443347 \\
81\end{array}$ & 0,654 & 225,80 & 6849,14 \\
\hline 78 & 152,568 & 0,0997 & $-152,7$ & $15,9870 \begin{array}{c}1,61930 \\
1\end{array}$ & $\begin{array}{c}0,00082 \\
3\end{array}$ & 0,82113 & 1278,96 & 80,821 & 15,8246 & $\begin{array}{l}12994,0 \\
96\end{array}$ & $\begin{array}{l}12994,0 \\
96\end{array}$ & 25988,2 & $\begin{array}{c}511578 \\
60\end{array}$ & 0,754 & 207,74 & $\begin{array}{c}13092,5 \\
7\end{array}$ \\
\hline 150 & $92, \overline{1452}$ & 0,1490 & $-92,3$ & $6,7197 \begin{array}{c}2,40375 \\
4\end{array}$ & $\begin{array}{c}0,00122 \\
1\end{array}$ & 1,21892 & 537,58 & 81,219 & 6,6189 & $\begin{array}{c}8067,85 \\
8 \\
\end{array}$ & $\begin{array}{c}8067,85 \\
8\end{array}$ & 16135,7 & $\begin{array}{c}317632 \\
20 \\
\end{array}$ & 0,468 & 54,21 & $\begin{array}{c}22044,2 \\
3 \\
\end{array}$ \\
\hline
\end{tabular}

The graphic (Figure 5) shows that a diver of $80 \mathrm{~kg}$ with a surface impact equal to $0,000508 \mathrm{~m} 2$ (foot in hyperextension) jumping from a height of $28 \mathrm{~m}$ finds its highest stimuli at $12994,525 \mathrm{~N}$ at $1.64 \mathrm{mt}$ of water penetration. The duration of the maximum stimuli is equal to 0.001 seconds.

As is easily understood, the diver's body, even for a short time, is subject to notable stimuli. 


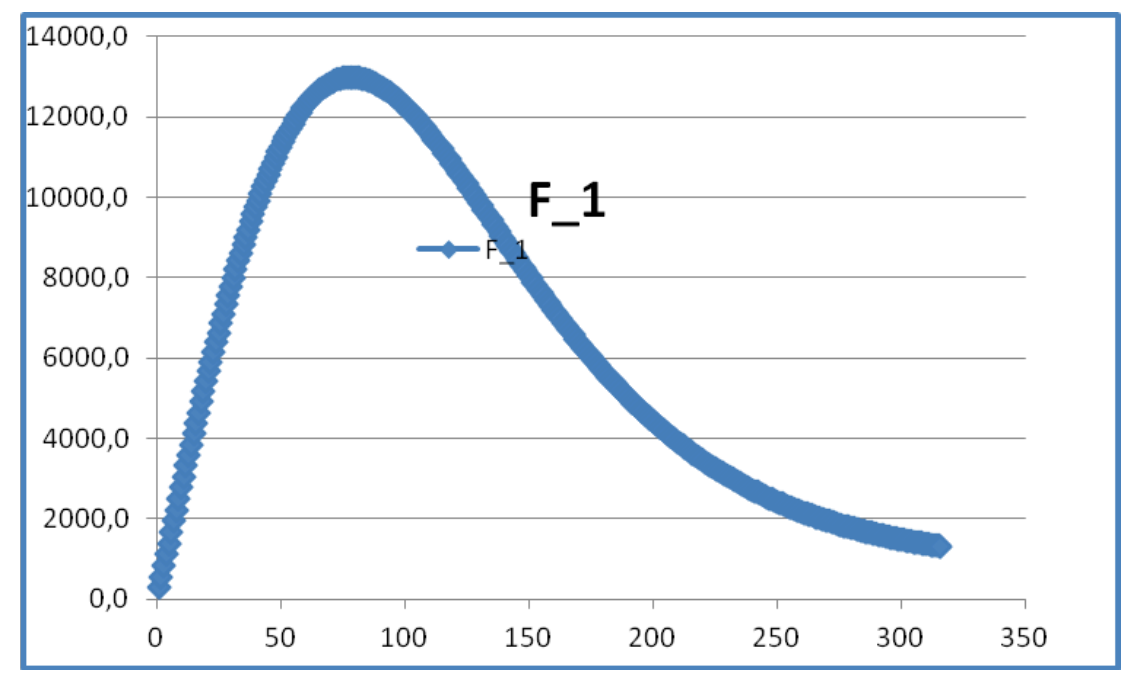

Figure 5. Highest stimuli.

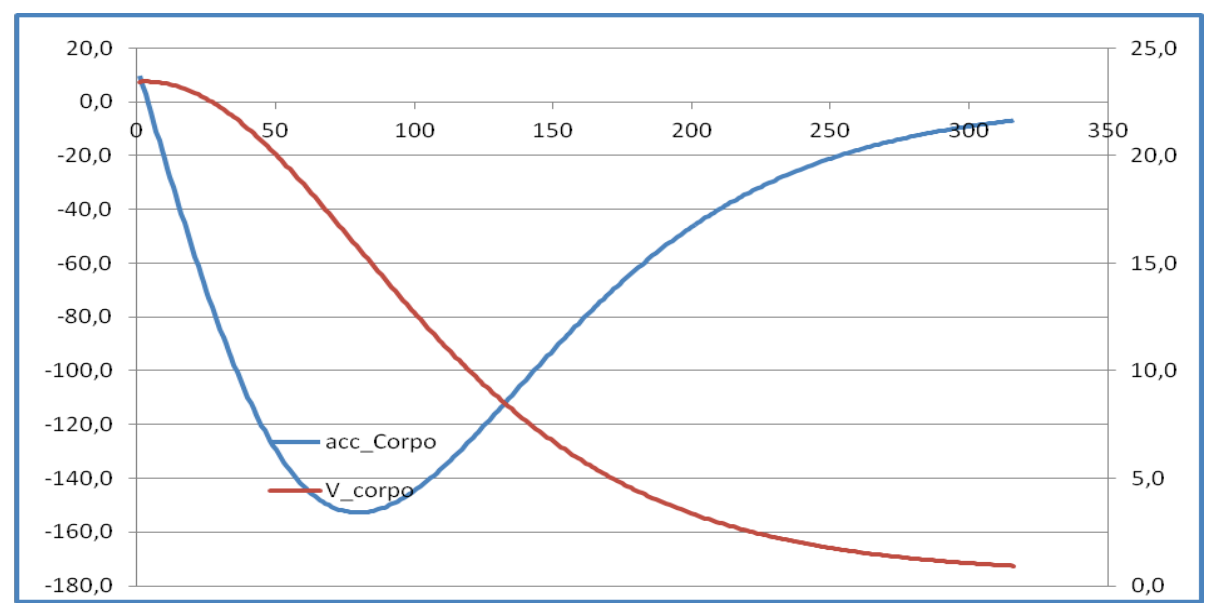

Figure 6. Speed/acceleration.

\section{METHODS}

The approach is integrated and composed by three methods: case study for the analysis of the single performance, action research for the contribution of the specialist (aerospace engineer) and the elaboration of data with theoretical deduction discussions. The study is based on a series of dives with different situations regarding water impact. The analysis instrument is the decoded video on behalf of the analyst, the researcher and the specialist in that category, previously divided, of the independent and the dependent variables of the data gathered with Kinovea software: having previously calculated an impact coefficient based on surface contact.

Furthermore a questionnaire was administered to six high level divers (the study is based on ten divers who perform this discipline) in order to gain ulterior data regarding the study. 


\section{RESULTS}

For each single dive taken into study, based on the results obtained from the analysis of the data collected, the influence of the impact and any eventual consequences will be calculated. Furthermore eventual technical errors in execution will be found in order to give the diver a series of data to be used to improve their performance and reduce to the minimum amount of damage given the water impact.

\section{DISCUSSION AND CONCLUSIONS}

The results of this study will supply a series of sufficient data and elements, able to supply athletes and their trainers a series of elements that will favour the elaboration of a coded methodology for teaching high diving techniques and will shed light on the organism's water impact.

\section{REFERENCES}

1. ALBRO JV, SOHL GA, BOBROW JE. On the Computation of Optimal High-Dives. International Conference on Robotics B Automation San Francisco, CA April 2000.

2. ALEXANDER RM. A minimum energy cost hypothesis for human arm trajectories. Biol Cybern. 1997; 76(2): 97-105.

3. BELL RL, BORGWARDT RE. The theory of high-altitude corrections to the US Navy Standard Decompression Tables. The Cross corrections. Undersea Biomed. Res. 1976; 3(1): 1-23.

4. BONI M, SCHIBLI R, NUSSBERGER P, BUHLMANN AA. Diving at diminished atmospheric pressure: air decompression tables for different altitudes. Undersea Biomed Res. 1976; 3(3): 189204.

5. BUHLMANN AA. Decompression/Decompression Sickness. Springer-Verlag, Berlin. 1984.

6. CRAWFORD LS, SASTRY SS. Biological motor control approaches for a planar diver. Proceedings of the 34th IEEE Conference on Decision and Control. 1995: 3881-3886.

7. DRYDEN IL, MARDIA KV. Statistical Shape Analysis. Chichester, New York: J. Wiley. 1998.

8. FEATHERSTONE R. The calculation of robot dynamics using articulated body inertias. International Journal of Robotics Research. 1983; 2(1): 13-29.

9. ISARD M, BLAKE A. Contour tracking by stochastic propagation of conditional density, In Proc. ECCV. 1996: 343-356.

10. ISARD M, BLAKE A. "Condensation-conditional density propagation for visual tracking". Int J Computer Vision. 1998; 29(1): 5-28.

11. JANG DS, CHOI HI. Active models for tracking moving objects. Pattern Recognition. 2000; 33(7): 1135-1146.

12. PAULEV P, ZUBIETA-CALLEJA G. High Altitude Diving Depths. Research in Sports Medicine. 2007; 15(3): 213-223.

13. RAIOLA G. Study between neurophysiological aspects and regulation documents on preschool in Italy. Journal of Physical Education and Sport. 2011; 11(1): $42-47$.

14. RICHARD G, SNYDER PHD, CLYDE C, SNOW MS. Fatal Injuries Resulting from Extreme water Impact. Reprinted from Aerospace Medicine.1967; 38(8).

15. VON KARMAN T. The impact of seaplane floats during loading. NACA TN 321, October, Washington. 1929.

16. XIONG Y, YI ZHANG A. Learning-based Tracking for Diving Motions. Proceedings of the Third International Conference on Image and Graphics (ICIG'04). 2004. 